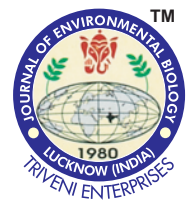

\title{
Comparison of zooplankton communities in the East Sea, East China Sea and Philippine Sea
}

\section{Authors Info \\ B.R. Lee ${ }^{1,3}$, W. Park ${ }^{1 *}$, H.K. Kang ${ }^{2}$, H.W. Lee ${ }^{3}$, H.S. Ji ${ }^{3}$ and J.H. Choi ${ }^{3}$ \\ ${ }^{1}$ Department of Marine Biology, Pukyong National University, Busan-48513, Korea \\ ${ }^{2}$ Korea Institute of Ocean Science and Technology, Busan-49111, Korea \\ ${ }^{3}$ National Institute of Fisheries Science Fisheries Resources Research Center, Tongyeong- 53064, Korea \\ *Corresponding Author Email : wpark@pknu.ac.kr}

\section{Edited by}

Professor Chung II Lee

\section{Reviewed by}

Professor Hyun Jei Park

Dr. Jung Nyun Kim

\begin{abstract}
Aim: To investigate the distribution pattern and species composition of zooplankton in relation to different water bodies.

Methodology: Zooplankton communities were investigated at 11 stations in the East Sea, three stations in the East China Sea and four stations in Philippine Sea. Sea surface temperature and salinity were simultaneously measured during the sampling.

Results: The mean sea surface temperature was highest in the Philippine Sea and lowest in the East Sea. Total 198 species of seven zooplankton phyla were identified. In the East Sea, copepods were most dominant (52\%), followed by amphipods (23\%). In the East China Sea, copepods comprised $86 \%$ of all zooplankton species with $5 \%$ mollusks. In the Philippine Sea, copepods accounted for $79 \%$ of all zooplankton species. Zooplankton densities were higher in the East China Sea than other seas, followed by the East Sea and the Philippine Sea. The species number of zooplankton was higher in the Philippine Sea than other seas. Warm water species was dominated in the Philippine Sea, followed by the East China Sea. Relative proportion of cold water species were higher in the East Sea than other seas.
\end{abstract}

Interpretation: Zooplankton communities were indicated by oceanographic characteristics of water bodies.

Key words: East Sea, Oceanic currents, Philippine Sea, Zooplankton communities

To investigate the zooplankton communities in relation to different water bodies
Oceanographic characteristics

$\begin{array}{ll}\text { Water temperature } & \text { Water salinity } \\ \text {-Philippine sea (highest) } & \text {-Philippine sea (highest) } \\ \text {-East Sea Sea } & \text {-East China Sea (lowest) } \\ \text { (lowest) } & \end{array}$

\section{Zooplankton communities}

Zooplankton densities -East China Sea (highest)

-Philippine sea (lowest)

Proportion of warm water species

-Philippine sea (highest) -East China Sea (lowest)

\section{Dominant species in each water mass}

- Philippine sea : Corycaeus speciosus, Ostracod spp., Oncaea venusta

- East China Sea : Paracalanus parvus s.l., Calanus sp. Copepodite, Oncaea venusta

- East Sea Sea : Corycaeus speciosus, Euchaeta rimana, Oncaea venusta

- Co-occurring species : Corycaeus speciosus, Euchaeta rimana, Oncaea venusta

\section{Zooplankton communities varied with different water bodies}

How to cite : Lee, B.R., W. Park, H.K. Kang, H. W. Lee, H. S. Ji and J. H. Choi: Comparison of zooplankton communities in the East Sea, East China Sea and Philippine Sea. J. Environ. Biol., 40, 861-870 (2019). DOI: http://doi.org/10.22438/jeb/40/5(SI)/SI-06 


\section{Introduction}

Zooplanktons are important constituents in most marine planktonic communities and play a role in the transfer of energy from phytoplankton to higher trophic levels (Liao et al., 2006). They maintain higher trophic levels and are important indicators of water masses. Zooplankton communities are influenced by oceanographic characteristic as well as biological interactions (Omondi et al., 2011). In particular, hydrographical properties of water masses play a major role in shaping zooplankton community structure and respond quickly to any changes (Mahesh et al., 2015). Calanoida are abundantly distributed in oligotrophic waters, cyclopoids and cladocerans are dominant in eutrophic waters (Wetzel, 1990).

The subtropical and temperate regions of northwestern Pacific Ocean are characterized by various water bodies: Eutrophic waters in the East China Sea and East Sea and an oligotrophic water in Western Pacific warm pool (Lee et al., 2012). The East China Sea is affected by coastal upwelling and river discharge from the north (Lee et al., 2012). It is a productive area in the west of Pacific Ocean (Wong et al., 2000) and is strongly affected by nutrient rich river such as Changjiang River (Zheng et al., 2015) and Kuroshio Currents to transport warm seawater (Ichikawa and Chae, 2002). Warm water species such as Nannocalanus minor, Undinular vulgaris and Paraeucalnaus attenuates representing the Kuroshio Current appear in the East China Sea (Zuo et al., 2006).

The East Sea marine environment is influenced by the Tsushima Warm Current and the North Korea Cold Current. The Tsushima Warm Current, which is a branch of the Kuroshio Current, flows northeastward through the Korean Strait from the ECS while the North Korea Cold Current, a branch of the Liman Current, does southward along the Korean coast (Rebstock and Kang, 2003). Cold water masses are strengthened during spring which cold water species such as Oithona atlantica and Metridia pacifica are dominant in the East Sea/Japan Sea. Warm water species such as Oncaea media, Clausocalanus sp., and Acartia pacifica become adundant when the Kuroshio Current overwhelms in fall (Kang et al., 2002).

The Philippine Sea is influenced by North Equatorial Current which feed the northward-flowing Kuroshio Current $(\mathrm{Qu}$ and Lukas, 2003; Qiu and Chen, 2010). Also, there is a warm pool where sea surface temperatures are highest in the world ocean (Ridout and Reynolds, 1998). The surface layer of the western warm pool is characterized by oli gotrophic system, which has high temperature, low nitrates, low salinity, low chlorophyll and deep thermocline (Allain et al., 2007). In the warm pool of northwestern Pacific Ocean, large planktonic copepods such as Eucalanus californicus and Rhincalanus sp. are predominant

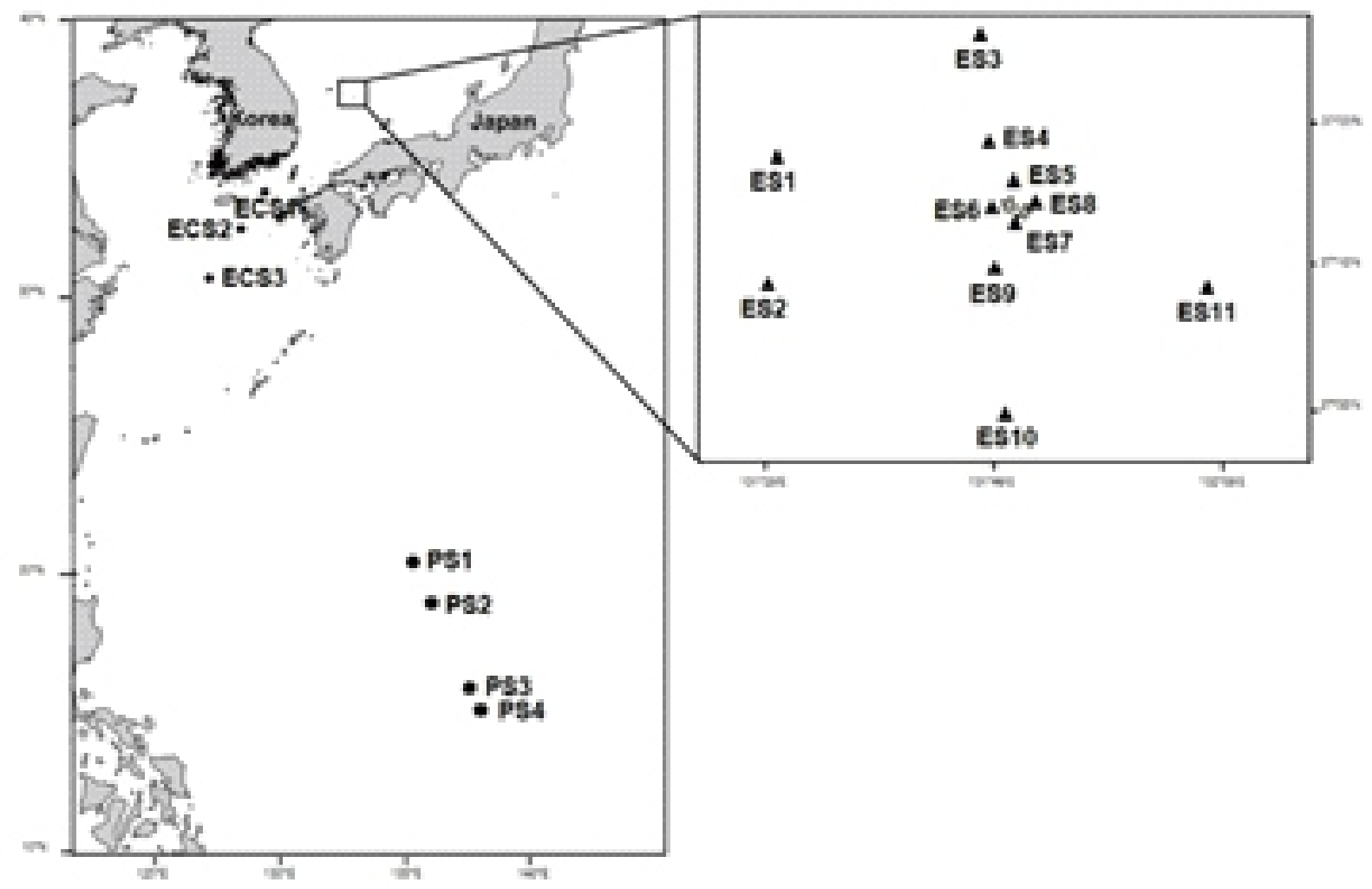

Fig. 1 : Sampling stations in the three seas in the subtropical and temperate regions of the northwestern Pacific Ocean in May 2012: The East Sea (ES111), East China Sea (ECS1-3) and Philippine Sea (PS1-4). 
(Shimode et al., 2012a, b).

Zooplankton communities vary with varying water masses. Three different study areas are located in northwestern Pacific Ocean, particularly in the way of Kuroshio Current. In the study area, the Kuroshio Current influences three study regions with different scales. Moreover, there are regional water mass characteristics such as warm pool, and river flows. In this respect, zooplankton communities vary with varying water masses.

The aim of this study was to investigate the distribution pattern and species composition of zooplankton in relation to different water bodies in the subtropical and temperate regions of the northwestern Pacific Ocean.

\section{Materials and Methods}

Zooplanktons were collected from 11 stations in the East Sea(ES1-11) in May 2011, three stations in the East China Sea (ECS1-3) and four stations in the Philippine Sea (PS1-4) in May 2013 (Fig. 1). A Bongo net with a mesh size of $200 \mu \mathrm{m}$ was obliquely towed. When the water depth was shallower than 300 $\mathrm{m}$, a Bongo net was towed from near bottom to surface, while water depth was deeper than $300 \mathrm{~m}$, it was towed at a $300 \mathrm{~m}$ depth to the surface. In the laboratory, zooplankton was identified to species level. Each sample was divided into subsamples finalizing 300-500 individuals in counting. During zooplankton sampling, temperature and salinity were measured with a CTD (Sea Bird 911 plus).

Zooplankton diversity was estimated by Shannon-Wiener diversity(Shannon and Weiner, 1963). To analyze similarity among stations, Bray-Curtis similarity index was determined. According to the index, cluster analysis (PRIMER 6.1.6) was calculated and showed images with the result of nMDS. When data were not fit into normal distribution, the data were transferred as $\log (x+1)$ analysis. Spearman rank correlation coefficient was used to compare the surface water temperature, surface water salinity and the densities of dominant common species in the East Sea, East China Sea and Philippine Sea.

\section{Results and Discussion}

Temperature and salinity: The mean sea surface temperature was highest in the Philippine Sea, and lowest in the East Sea. In the Philippine Sea, the mean sea surface temperature was higher than $28^{\circ} \mathrm{C}$. The mean sea surface salinity was lowest in the East China Sea. Sea surface salinity was 32.6 at ECS3 in the East China Sea (Fig. 2).

Species composition and abundance : Total 98 species of zooplankton of seven phyla were identified. Among these, 116 copepod species of 46 genera were identified. Zooplankton species at each sea ranged from 22 to $65 \mathrm{spp}$. Zooplankton
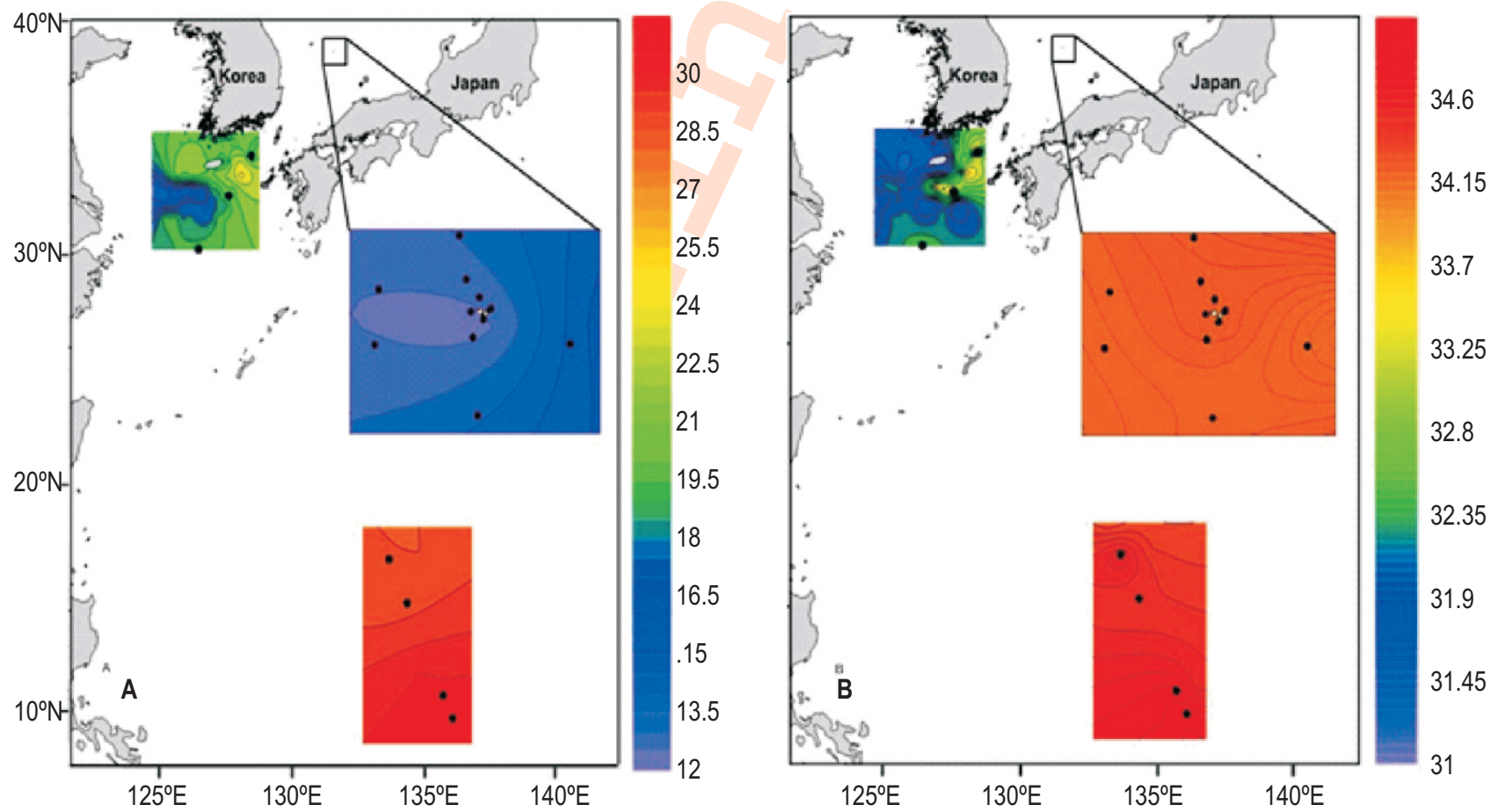

Fig. 2 : Sea surface temperatures $(A)$ and salinities $(B)$ at sampling stations in the subtropical and temperate regions of the northwestern Pacific Ocean: East Sea, East China Sea and Philippine Sea in May 2012. 


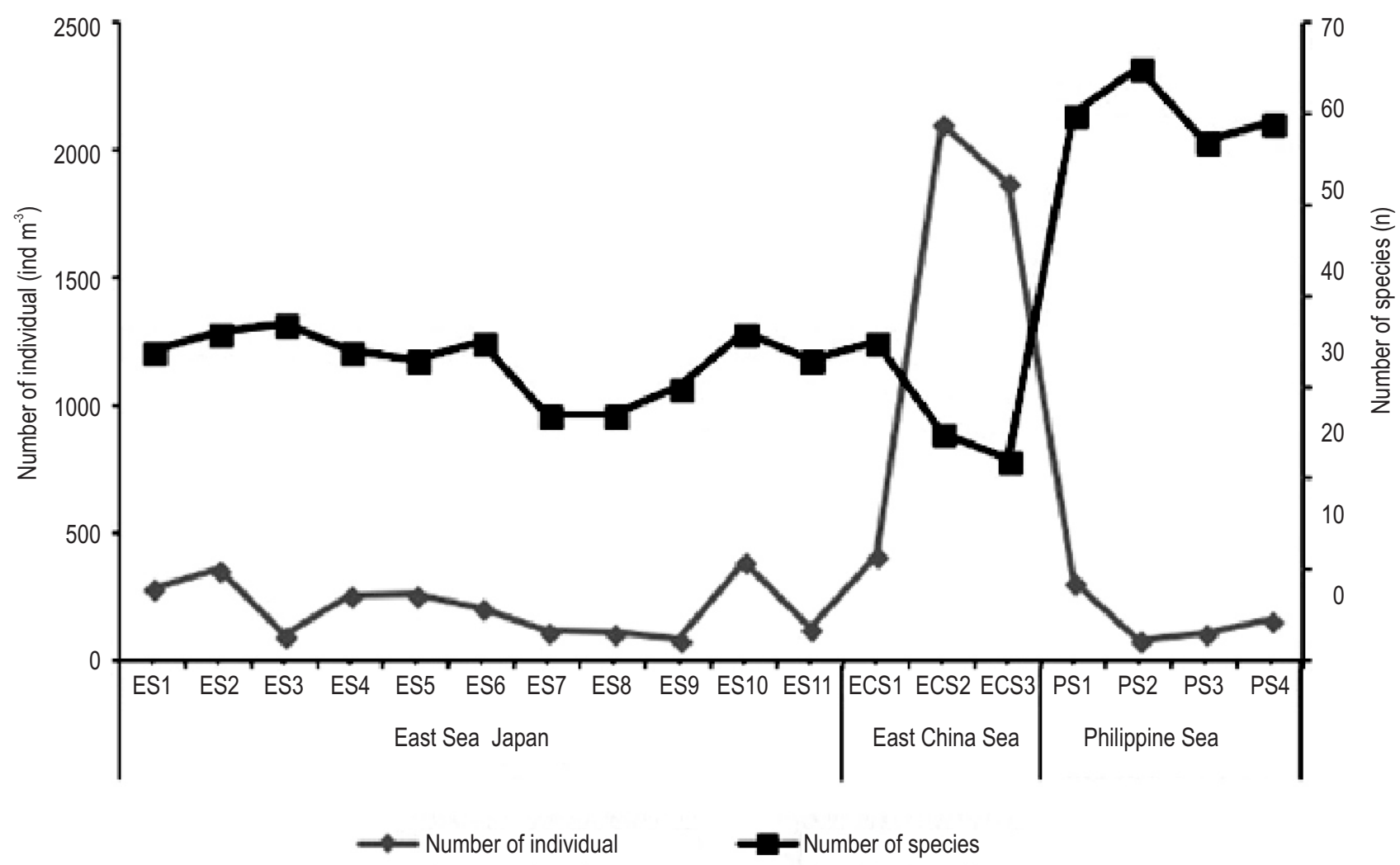

Fig. 3 : Number of species and abundance at sampling stations in the subtropical and temperate regions of the northwestern Pacific Ocean: East Sea, East China Sea and Philippine Sea in May 2012.

species was highest at PS2 in the Philippine Sea, while the lowest at ECS3 in the East China Sea (Fig. 3). Zooplankton densities varied from 79.4 to $2,100.4$ ind. $\mathrm{m}^{-3}$. The zooplankton densities were highest in the East China Sea $\left(407.4-2100.4\right.$ ind $\left.\mathrm{m}^{-3}\right)$, while they were lowest in the Philippine Sea $\left(79.4-306.7\right.$ ind. $\mathrm{m}^{-3}$ ) (Fig. 3 , 4).Copepod species were composed of $50 \%$ of zooplankton species in all the seas.

In the East Sea, copepod densities were highest (52\%), followed by amphipods $(23 \%)$ and chordates $(11 \%)$. In the East China Sea, copepods comprised $86 \%$ of all zooplankton species with 5\% mollusks. In the Philippine Sea, copepods accounted for $79 \%$ of all zooplankton species (Fig. 5).Shannon-Wiener diversity indices among stations ranged between 1.8 and 3.8. Species diversity was relatively higher in the Philippine Sea than other seas (Fig. 6). In the East Sea/Japan Sea, three most dominant species were Themisto spp. juvenile, Oithona atlantica and Metridia pacifica. Themisto spp. juvenile was the most dominant species and occurred at all stations, except ES2. In the East China Sea, Paracalanus parvus, Calanus spp. copepodite and Oncaea venusta were relatively abundant. Among these species, Paracalanus parvus s.l. was the most abundant species and occurred at all stations of the East China Sea. Corycaeus speciosus, Ostracod spp. and Calanid spp. copepodite were dominant in the Philippine Sea. Corycaeus speciosus was the most abundant species, followed by Ostracod spp. and Calanid spp. copepodite (Fig. 7).

The community of zooplankton is known to be closely linked to oceanographic characteristics of water mass. The East/Japan Sea is influenced by northward flowing the Kuroshio warm Current and southward flowing the North Korea Cold Current (Ashjan et al., 2005; Kwak et al., 2014). Currents in the East Sea/Japan Sea vary with seasons. In spring, the Tsushima Current is weak. Cold water is highly variable in ES and cold phase emerges during late spring (Mitchell et al., 2005). Zooplankton composition also varies with seasons. Zooplankton composition was dominated by copepods which comprised $60 \%$ of total numerical abundance, followed by other crustaceans (27\%) and appendicularians (4\%) in May. Cold-water species such as Pseudocalanus minutus, Metridia pacifica and Oithona atlantica were also abundant in May (Kang et al., 2002). In this study, zooplankton abundance was lower than previous studies, while species composition was similar to that reported by Kang et al. (2002). This result suggests that the East Sea/Japan Sea was influenced by cold water and dominated by cold water species during spring.

The water masses of the East China Sea varies with seasonal patterns (Gong et al., 1996). The East China Sea is 


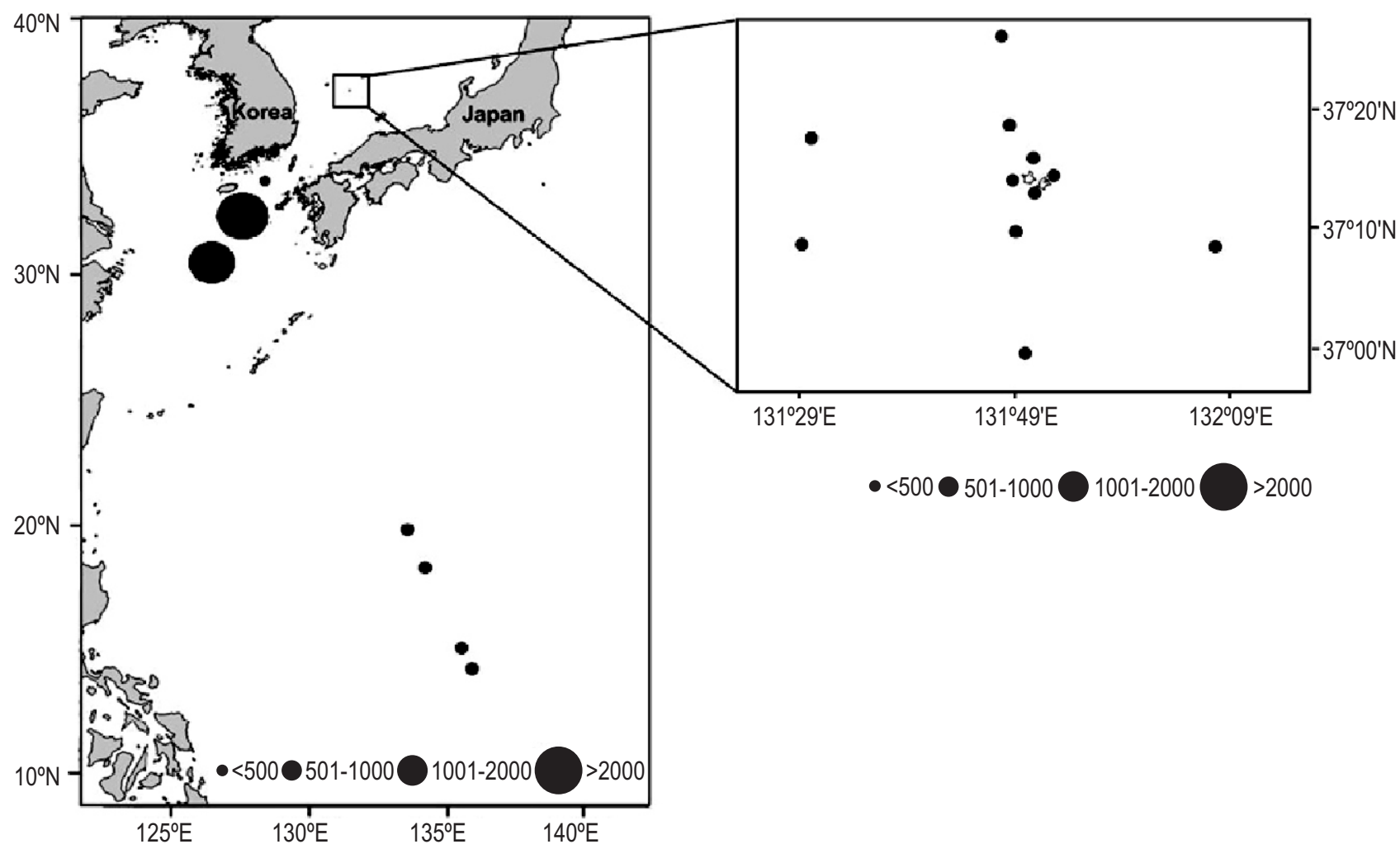

Fig. 4 : Zooplankton densities in the subtropical and temperate regions of the northwestern Pacific Ocean: The East Sea, East China Sea and Philippine Sea in May 2012.

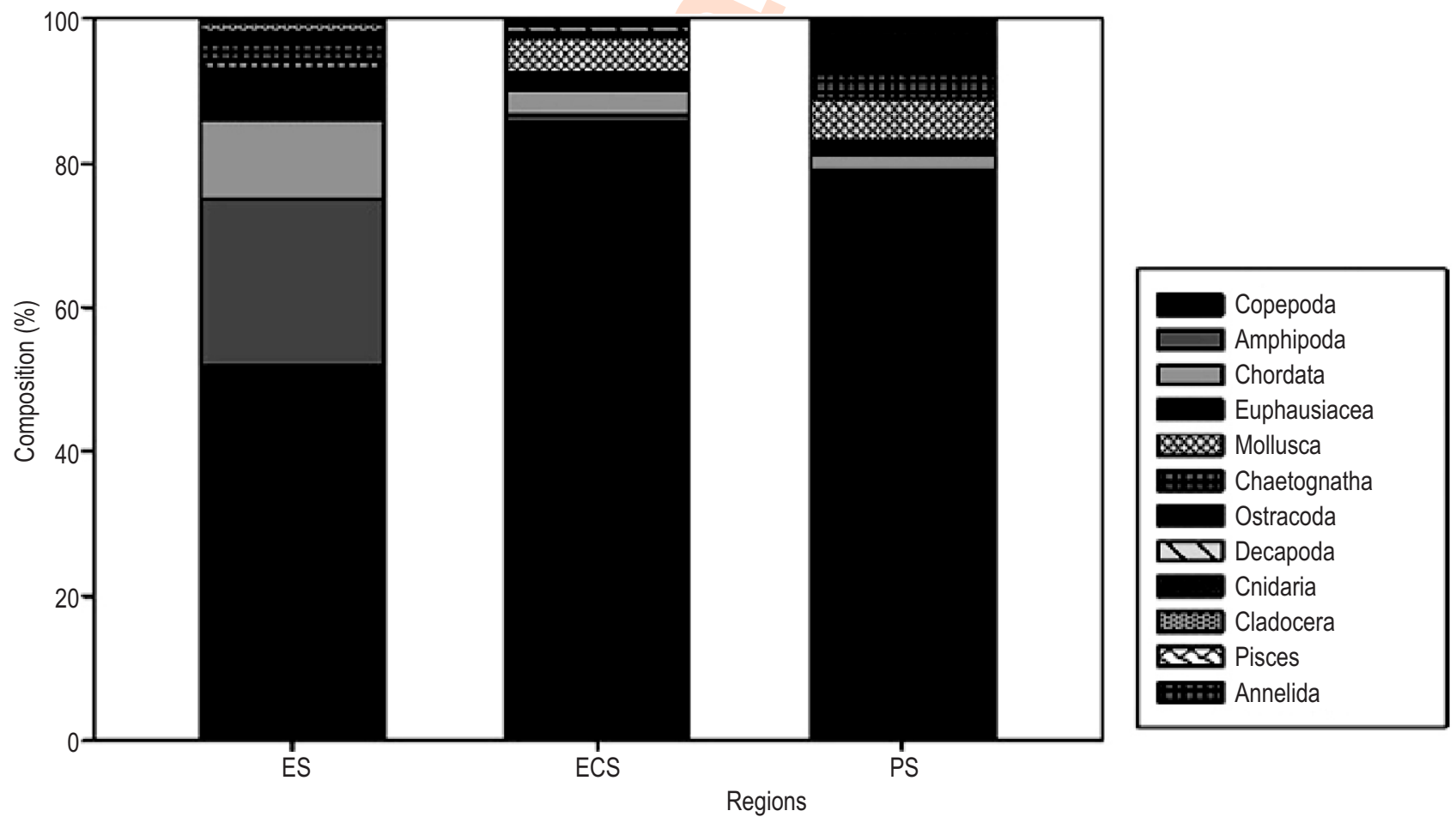

Fig. 5 : Taxon composition of zooplankton in the subtropical and temperate regions of the northwestern Pacific Ocean: The East Sea, East China Sea and Philippine Sea in May 2012. 


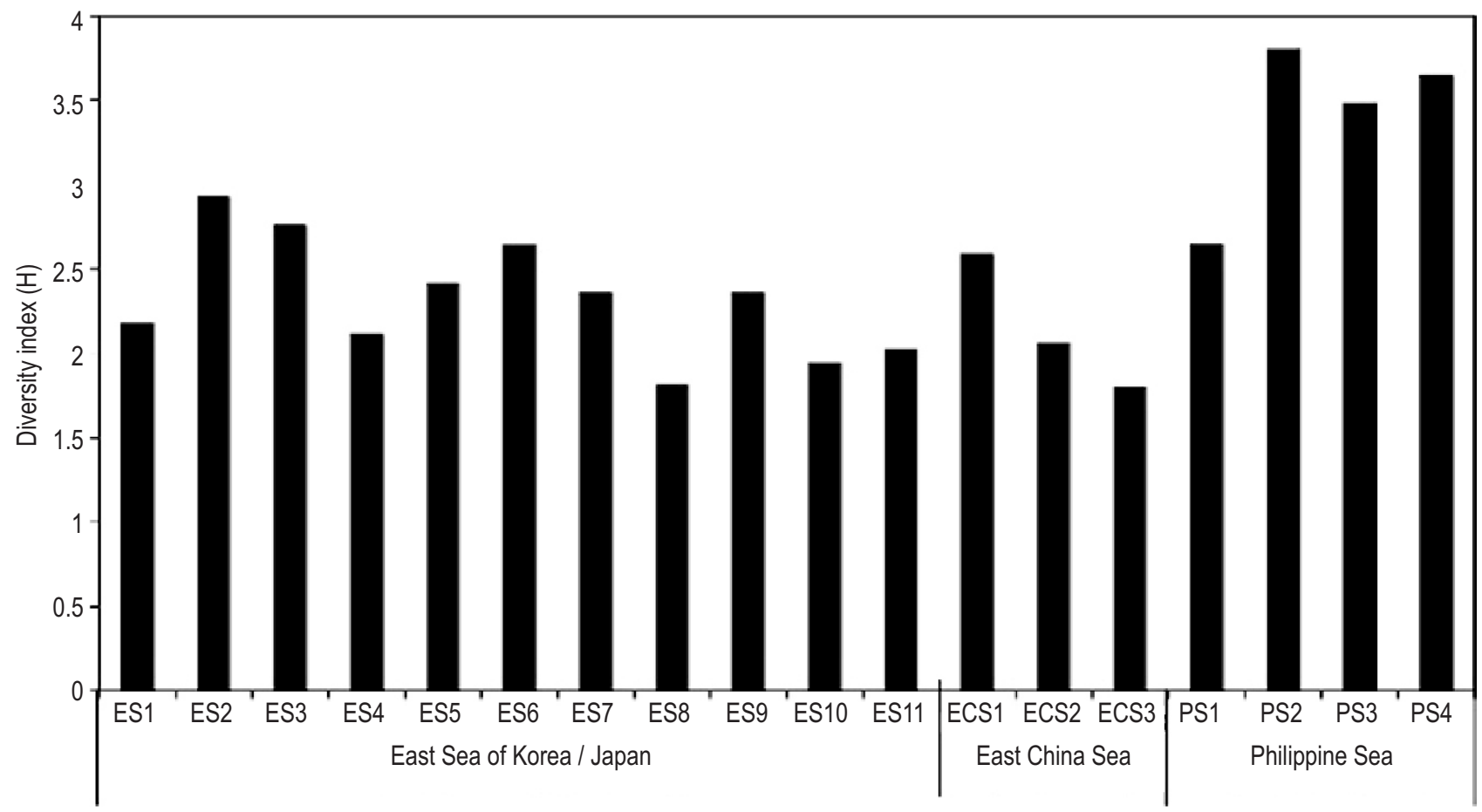

Fig. 6 : Shannon-Wiener diversity index of each station in the subtropical and temperate regions of the northwestern Pacific Ocean: The East Sea, East China Sea and Philippine Sea in May 2012.

strongly influenced by freshwater inputs and the warm Kuroshio Current. In general, the mean semi-monthly strength and flows of the warm Kuroshio Current are maximum in late spring and minimum in October (Kawabe, 1988). However, the seasonal variation of current is different from year to year (Oka and Kawabe, 1998). In the East China Sea, zooplankton density was 1,915 ind $\mathrm{m}^{-3}$. Copepods were the most abundant, comprising over $80 \%$. Copepods belonging to family Paracalanidae occurred more than $40 \%$ of total zooplankton abundance, followed by the species of families Oncaeidae (18\%) and Oithonidae (14\%) (Lee et al., 2011). Calanus sinicus, Euchaeta concinna, Paracalanus aculeatus, Oithona similis and Ditrichocorycaeus affinis occurred in more than $80 \%$ and were the most abundant species (Zue et al., 2006). In this study, zooplankton densities in the East China Sea were relatively higher than other Seas. Also, dominant species were similar to the previous studies of Lee et al. (2011) and Zue et al. (2006). In particular, warm temperate species such as Calanus sinicus was common in the East China Sea. C. sinicus are affected by ocean currents with their distribution and life history strategies, being regarded as a biological indicator to the evidence of water movements (Hwang and Wong, 2005). The present result indicates that the East China Sea in spring was affected by the warm Kuroshio Current.

The Philippine Sea includes various trophic systems from oligotrophic waters and more productive waters (East China Sea) (Lee et al., 2012). In the Philippine Sea, zooplankton density was
967 ind. $\mathrm{m}^{-3}$. Mesozooplankton abundance was low and species smaller than $1 \mathrm{~mm}$ in body lengths were dominated(56\%) in the Philippine Sea. Small copepods were dominant including species of families Oncaeidae (20.7\%), Oithonidae (20\%) and Clausocalanidae (14.3\%) (Lee et al., 2012). The present results corroborate with previous studies of Lee et al. (2012). Small copepods are relevant to inhabit the warm waters because they have high fecundity and growth rates and are less limited by insufficient food environments (Turner, 2004).

Co-occurring species and environmental factor: Corycaeus speciosus was found in ES2, ECS1 and PS1-3. C. speciosus was most abundant in the Philippine Sea with densities ranging from 1.7 - 138.9 ind. $\mathrm{m}^{-3}$. The density of $C$. speciosus was not correlated with sea water temperature $(r=0.375 ; p>0.05)$, nor salinity $(r=0.215 ; p>0.05)$ (Table 1$)$. The densities of $E$. rimana ranged from $0.01-3.2$ ind. $\mathrm{m}^{-3}$ and occurred at ES9, ECS2 and PS2-PS4. The highest density of E. rimana was at PS3 in the Philippine Sea. The densities of $E$. rimana were significantly correlated with sea water temperatures $(r=0.633 ; p<0.01)$, while not with salinities $(r=0.396 ; p>0.05)$. O. venusta appeared at $E S$, ECS1, ECS2 and PS3. The densities of $O$. venusta ranged from $0.01-240.8$ ind. $\mathrm{m}^{-3}$. The density of 0 . venusta was relatively higher at ESC2 of the East China Sea, but lower at PS3 of the Philippine Sea. The densities of $O$. venusta were not significantly correlated with sea water temperatures $(r=0.319 ; p>0.05)$ and salinities $(r=0.121 ; p>0.05)$ (Fig. 8). 


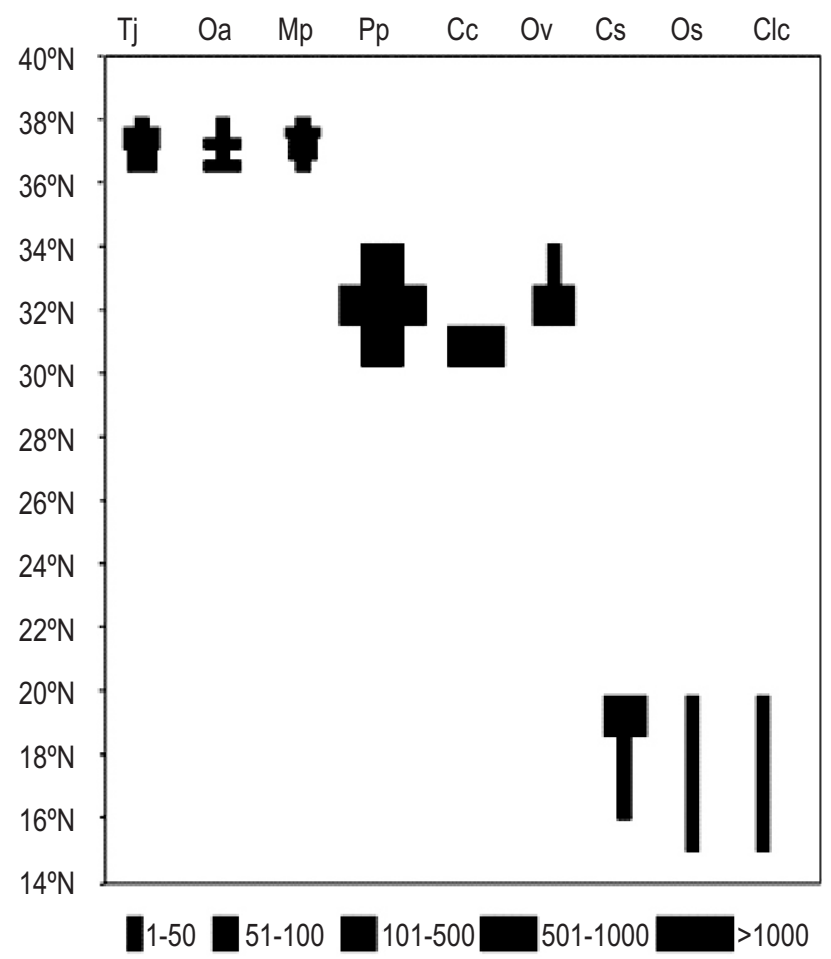

Fig. 7 : Distribution of dominant species in the East Sea, East China Sea and Philippine Sea in May 2012. Tj: Themisto spp. juvenile, Oa: Oithona atlantica, Mp: Metridia pacifica, Pp: paracalanus parvus s.I., Cc: Calanus sp. copepodite, Ov: Oncaea venusta, Cs: Corycaeus speciosus, Os: Ostracoda spp., Clc: Calanid spp. copepodite.

The members of family Corycaeidae are widely distributed in temperate and tropical waters, associated with warm currents (Vidjak and Bojanić, 2009). Among the members, Corycaeus speciosus is represented mainly by oceanic region species. The front zone of East Sea were influenced by warm current than cold one, with C. speciosus showing diversity of 48.6 ind. $\mathrm{m}^{-3}$ (Park and Choi, 1997). C. speciosus occurred comprising $0.34-3.64 \%$ in the southern East China Sea (Shih and Chiu, 1998). The species of family Corycaeidae was third dominant species (15\%) in warm pool (15\%) (Lee et al., 2011). In this study, C. speciosus was found in all three seas and corroborate with the previous study of Lee et al. (2011). However, temperature and salinity showed insignificant correlation. The results reveal that $C$. speciosus is distributed in oceans irrespective of water temperature and salinity.

Euchaeta rimana is a subtropical, open-ocean copepod common in the plankton of North Pacific central gyre (Yen et al., 1991). The abundance of $E$. rimana is maximum in the oceanic waters of eastern and southeastern Hong Kong (Wong et al., 2012). This species is found in the East China Sea, where water temperature and salinity are high, supposed to be influenced by warm Kuroshio Water (Zue et al., 2006; Tseng et al., 2008). In the

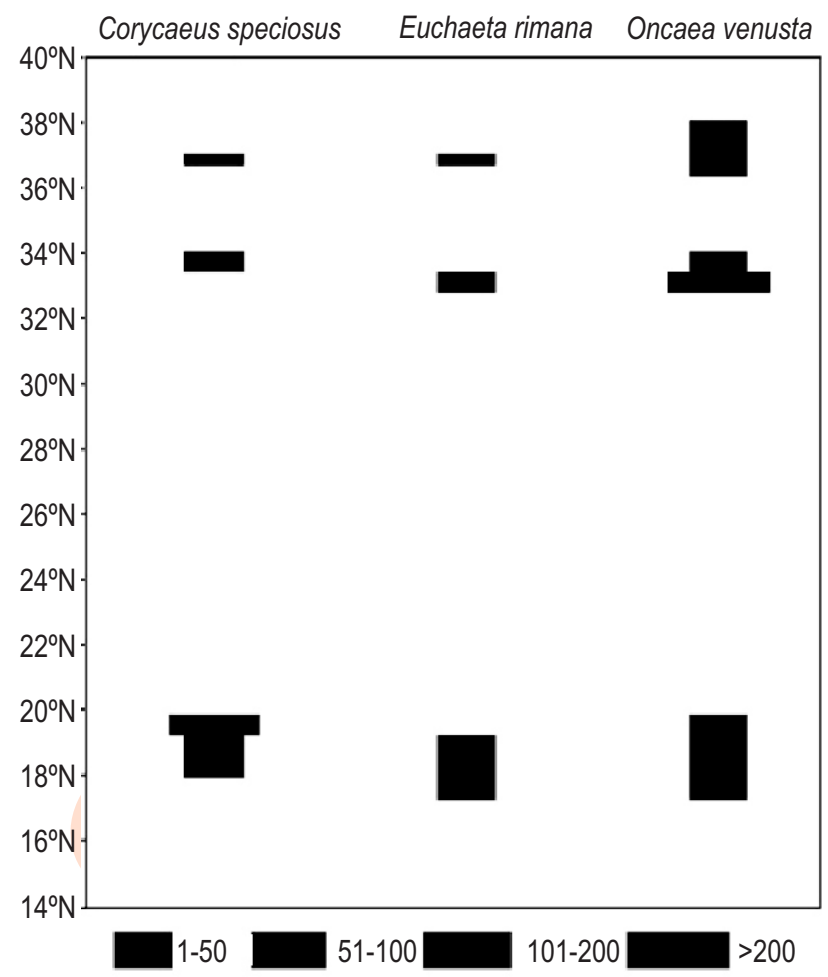

Fig. 8 : Distribution of co-occurring species in the East, East China Sea and Philippine Sea in May 2012.

present study, E. rimana occurred in all three seas. Therefore, the occurrence of $E$. rimana in three seas may be carried by the warm Kuroshio Current into three seas.

Oncaea venusta is widely distributed in different oceans. 0 . venusta is dominant during summer in the northern Taiwan Strait (Hsieh and Chiu, 2002; Lee et al., 2009) and is relatively abundant in the East China Sea and Taiwan Strait during spring and fall (Hsio et al., 2011). In the present study, O. venusta dominated in the Philippine Sea although the occurrence of this species is not correlated with temperature and salinity. However, small size copepods were abundant at the subsurface layer of Philippine Sea, where chlorophyll was maximum and composed mainly of small-size phytoplankton (Taniguchi, 1977). The sampling of present study was not made by different water layers. However, the occurrence of 0 . venusta was supposed to be influenced food conditions at the subsurface layer in the Philippine Sea.

Zooplankton community : The stations were classified into four groups at $40 \%$ level of similarity. 11 stations in the East/Japan Sea and four stations in the Philippine Sea were grouped one. Stations in the East China Sea were divided into two groups, one group of ESC1 and ESC2 and the other one of ESC3 (Fig. 9). The results of cluster-analysis by Bray-Curtis similarity indicated grouping of stations within similar water bodies. Zooplankton in the East Sea Sea were represented by high abundance of cold 
Table 1: Results of Spearman rank correlation coefficient between common species and environmental factors in the East Sea, East China Sea and Philippine Sea in May 2012

\begin{tabular}{lllll}
\hline Parameters & \multicolumn{2}{c}{ Temperature } & \multicolumn{2}{c}{ Salinity } \\
\hline & $r$ & $p$ & $r$ & $p$ \\
Corycaeus speciosus & 0.375 & $>0.05$ & 0.215 & $>0.05$ \\
Euchaeta rimana & 0.633 & $<0.01$ & 0.396 & $>0.05$ \\
Oncaea venusta & 0.319 & $>0.05$ & 0.121 & $>0.05$ \\
\hline
\end{tabular}

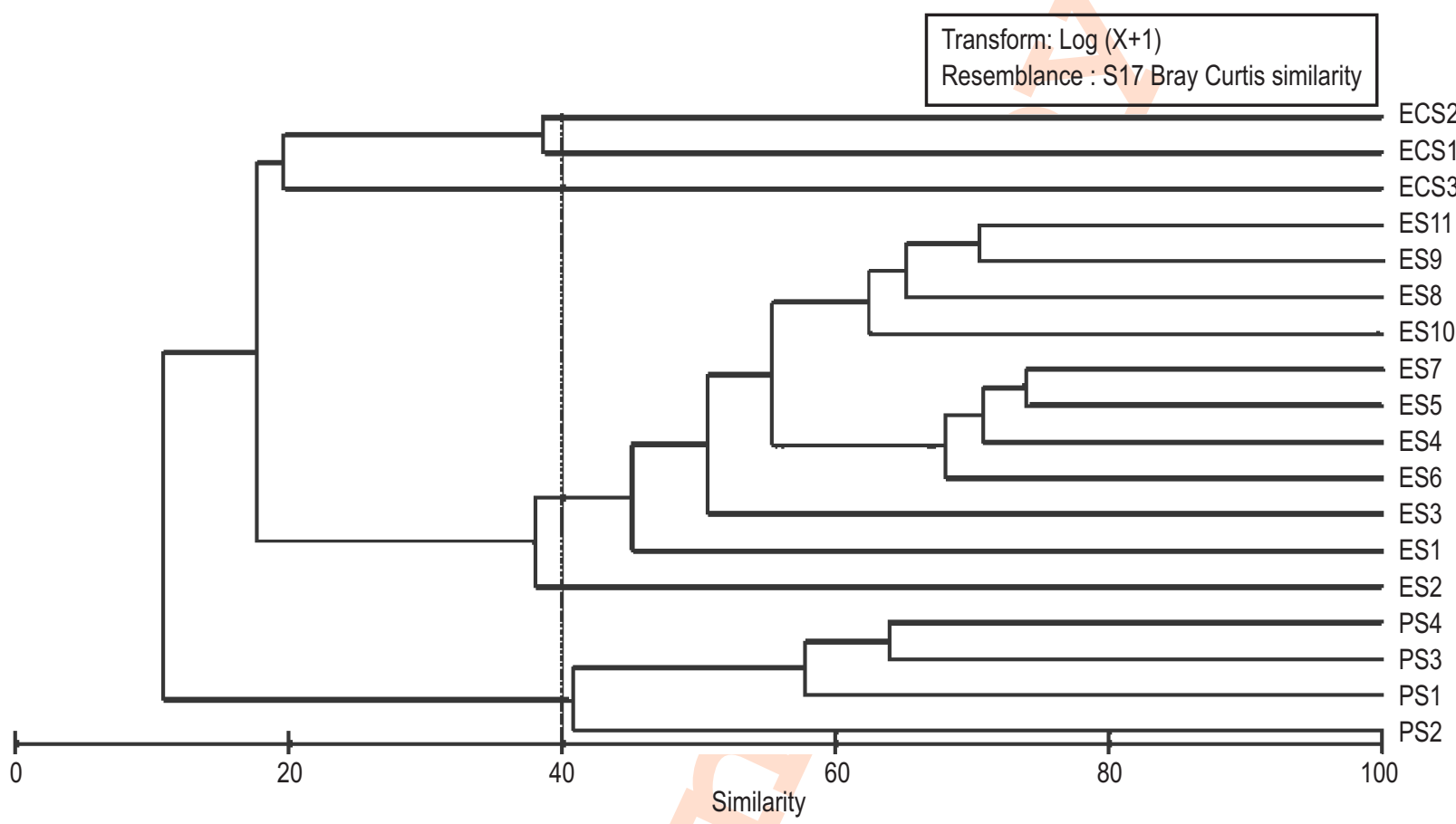

Fig. 9 : Comparison of zooplankton distribution between stations based on a cluster analysis using log10-trnasformd abundance data and Bray-Curtis dissimilarity index.

water species such as Themisto spp. juvenile, Oithona atlantica and Metridia pacifica. Those within northerner stations in the East China Sea included relatively smaller species such as Paracalanus parvus s.I., Oncaea venusta, Atlanta sp., Corycaeus robustus and Oithona longispina. The southern most station in the East China Sea retained Calanus spp. copepodite, Paracalanus parvus s.l., Corycaeus affinis, calanid copepodites and Paracalanus spp. copepodites. Those in the Philippine Sea consisted of various tropical species, such as Oncaea mediterranea, Cosmocalanus darwinii and Euchaeta plana.

The composition of zooplankton communities are influenced by water masses. Base on the habitat by water mass, zooplankton are usually categorized as warm-temperate species, eurythermal and low saline species, tropical species and cold water species (Chen, 1994). In the present study, four groups of zooplankton were divided by three seas. Oithona atlantica, Metridia pacifica and Paracalanus aculeatus were widely distributed in the East Sea Sea. Paracalanus aculeatus is carried by cold water mass (Dur et al., 2007). Oithona atlantica and Metridia pacifica are indicator species of cold water (Kang et al., 2002; Lan et al., 2009). Cold water species had higher composition of total zooplankton caused by the cold water input of Liman Current (Kang et al., 2002).

Zooplankton in the East China Sea was clustered into two groups. A few tropical species, e.g. Calanus sinicus and Undinula vulgaris, which can be included in the Kuroshio species, were found at ECS1 and ECS2 stations. Calanus sinicus is a temperate species, inhabiting temperature range of $5-23^{\circ} \mathrm{C}$ (Chen, 1992). Undinular vulgaris are found in warm saline water (Zue et al., 2006). ECS3 station did not have any water indicator species, which may be restrict their distribution only to this region. Therefore, the East China Sea can be indicated by a mixed water community by warm and saline Kuroshio Current and temperate water. 
Cosmocalanus darwinii occur in large number in the Kuroshio Current (Lo et al., 2014). Pleuromamma gracilis is an indicator species of tropical water (Lee et al., 2011) and distributed in the warm-core eddy (Strzelecki et al., 2007). Tropical species are centered on the warm pool of the Philippine Sea, where Cosmocalanus darwinii and Pleuromamma gracilis were also present.

The Kuroshio Current affected all the study areas. The results conclude that zooplankton communities were influenced by the oceanographic characteristics of water bodies.

\section{Acknowledgments}

The authors would also like to thank the anonymous referees for valuable comments that have greatly improved this article. This work was supported by a grant from the National Institute of Fisheries Science (R2019019).

\section{References}

Allain, V., S. Nicol, T. Essington, T. Okey, B. Olson and D. Kirby: An ecopath with Ecosim model of the Western and Central Pacific Ocean warm pool pelagic ecosystem. Scientific Committee Third Regular Session, WPFC, Honolulu, USA (2007).

Ashgian, C.J., C.S. Davis, S. M.Gallager and P. Alatalo: Characterization of the zooplankton community, size composition and distribution in relation to hydrography in the Japan/East Sea. Deep Sea Res. II., 51, 1363-1392 (2005).

Chen, Q.C.: Zooplankton of China Seas. Science Pr., Beijing, 1, 1-87 (1992).

Chen, Q.C.: Zooplankton in China Seas. In: Oceanology of China Seas. Springer Netherlands, 1, 243-254 (1994).

Dur, G., J.S. Hwang, S. Souissi, L.C. Tseng, C.H. Wu, S.H. Hsiao and Q.C. Chen: An overview of the Influence of hydrodynamics on the spatial and temporal patterns of calanoid copepod communities around Taiwan. J. Plankton Res., 29, i97-i116 (2007).

Gong, G.C., Y.L.L. Chen and K.K. Liu: Chemical hydrography and chlorophyll a distribution in the China Sea in summer: Implication in nutrient dynamics. Cont. Shelf Res. 16, 1561-1590 (1996).

Hsiao, S.H., S. Kâ, T. H. Fang and J.S. Hwang: Zooplankton assemblages as indicators of seasonal changes in water masses in the boundary waters between the East China Sea and the Taiwan Strait. Hydrobiologia, 666, 371-330 (2011).

Hsieh, C.H. and T.S. Chiu: Summer spatial distribution of copepods and fish larvae in relation to hydrography in the northern Taiwan Strait. Zool. Stud., 41, 85-98 (2002).

Hwang, J.S. and C.K. Wong: The China coastal current as a driving force for transporting Calanus sinicus (Copepoda: Calanoida) from its population centers to waters of Taiwan and Hong Kong during the NE monsoon period in winter. J. Plankton Res., 27, 205-210 (2005).

Ichikawa, H. and M. Chaen: Seasonal variation of heat and freshwater transports by the Kuroshio in the East China Sea. J. Mar. Syst., 24, 119-129 (2000)

Kang, J.H., W.S. Kim and J.H. Shim: Species composition and abundance of zooplankton community in spring and autumn around Dokdo. Ocean Polar Res., 24, 407-417 (2002).
Kawabe, M.: Variability of Kuroshio velocity assessed from the sea-level difference between Naze and Nishinoomote. J. Oceanogr. Soc. Japan, 44, 293-304 (1988).

Kwak, J.H., S.H. Lee, J.S. Hwang, Y.S. Suh, H.J. Park, K.I. Chang, K.R. Kim and C.K. Kang: Summer primary productivity and phytoplankton community composition driven by different hydrographic structures in the East/Japan Sea and the Western Subarctic Pacific. J. Geophys. Res. Oceans, 119, 4505-4519, (2014).

Lan, Y.C., M.A. Lee, C.H. Liao and K.T. Lee: Copepod community structure of the winter frontal zone induced by the Kuroshio branch Current and the China Coastal Current and the China Coastal Current in the Taiwan Strait. J. Mar. Sci Tech-Taiwan, 17, 1-6 (2009).

Lee, C.R., H.K. Kang and K.H. Choi: Latitudinal distribution of mesozooplankton community in the Northwestern Pacific Ocean. Ocean Polar Res., 33, 337-347 (2011).

Lee, C.R., K.H. Choi, H.K. Kang, E.J. Yang, J.H. Noh and D.H. Choi: Biomass and trophic structure of the plankton community in subtropical and temperate waters of the northwestern Pacific Ocean. J. Oceanogr., 68, 473-482 (2012).

Lee, C.Y., D.C. Liu and W.C. Su: Seasonal and spatial variations in the planktonic copepod community of llan bay and adjacent Kuroshio waters off northeastern Taiwan. Zool. Stud., 48, 151-161 (2009).

Liao, C.H., W.J. Chang, M.A. Lee and K.T. Lee: Summer distribution and diversity of copepods in upwelling waters of the southeastern East China Sea. Zool. Stud., 45, 378-394 (2006).

Lo, W.T., H.U. Dahms and J.S. Hwang: Water mass transport through the northern Bashi Channel in the northeastern South China Sea affects copepod assemblages of the Luzon Strait. Zool. Stud., 53, 66-74 (2014).

Mahesh, R., A. Saravanakumar, T. Thangaradjou and H.U. Solanki: Influence of environmental parameters in phyto and zooplankton assemblages in the Tamil Nadu coast, south-western Bay of Bengal. J. Coast. Sci. 2, 12-33 (2015).

Mitchell, D. A., D.R. Watts, M. Wimbush, W.J. Teague, K.L. Tracey, J.W. Book, K.I. Chang, M.S. Suk and J.H. Yoon: Upper circulation patterns in the Ulleung Basin. Deep Sea Res.II. Top. Stud. Oceanogr., 52, 1617-1638 (2005).

Oka, E. and M. Kawabe: Characteristics of variations of water properties and density structure around the Kuroshio in the East China Sea. J. Oceanogr., 54, 605-617 (1998).

Omondi, R., A.W. Yasindi and A. Magana: Spatial and temporal variations of zooplankton in relation to some environmental factors in Lake Baringo, Kenya. Eger. J. Sci. Technol., 11, $29-50$ (2015).

Park, C. and J.K. Choi: Zooplankton community in the front zone of the East Sea of Korea (the Sea of Japan): Species list, distribution of dominant taxa, and species association. Korean J. Fish. Aquat. Sci., 30, 225-238 (1997).

Qiu, B. and S. Chen: Interannual-to-decadal variability in the bifurcation of the North Equatorial current off the Philippines. J. Phys. Oceanogr., 40, 2525-2538 (2010).

$\mathrm{Qu}, \mathrm{T}$. and R. Lukas: The bifurcation of the North Equatorial current in the Pacific. J. Phys. Oceanogr., 33, 5-18 (2003).

Rebstock, G.A. and Y.S. Kang: A comparison of three marine ecosystems surrounding the Korean peninsula responses to climate change. Prog. Oceanogr., 59, 357-379 (2003).

Ridout, J.A. and C.A. Reynolds: Western Pacific warm pool region sensitivity to convective triggering by boundary lyer thermals in the 
NOGAPS atmospheric GCM. J. Climate, 11, 1553-1573(1998).

Shannon, C.E. and W. Weiner: The mathematical theory of communication. Univ. of Illinois Press, Urbana, USA (1964).

Shih, C.T. and T.S. Chiu: Copepod diversity in the water masses of the southern East China Sea north of Taiwan. J. Mar. Syst., 15, 533542 (1998).

Shimode, S., K. Takahashi, Y. Shimizu, T. Nonomura and A. Tsuda: Distribution and life history of the planktonic copepod, Eucalanus californicus, in the northwestern Pacific: Mechanisms for population maintenance within a high primary production area. Prog. Oceanogr., 96, 1-13 (2012a).

Shimode, S., K. Takahashi, Y. Shimizu, T. Nonomura and A. Tsuda: Distribution and life history of two planktonic copepods, Rhincalanus nasutus and Rhincalanus rostrifrons, in the northwestern Pacific Ocean. Deep Sea Res. I., 65, 133-145 (2012b).

Strzelecki, J., J.A. Koslow and A. Waite: Composition of mesozooplankton communities from a pair of warm- and cold-core eddies off the coast of Western Australia. Deep Sea Res. II., 54, 1103-1112 (2007).

Taniguchi, A.: Distribution of microzooplankton in the Philippine Sea and the Celebes Sea in the summer, 1972. J. Oceanogr. Soc. Japan, 33, 82-89 (1977).

Tseng, L.C., S. Souissi, H.U. Dahms, Q.C. Chen and J.S. Hwang: Copepod communities related to water masses in the southwest East China Sea. Helgol. Mar. Res., 62, 153-165 (2008).
Turner, J.T.: The importance of small planktonic copepods and their roles in the pelagic marine food webs. Zool. Stud., 43, 255-266 (2004).

Vidjak, O. and N. Bojanić: Species composition and distribution patterns of the family Corycaeidae Dana, 1852 (Copepoda: Cyclopoida) in the middle Adriatic Sea. Mar. Biol. Res., 5, 427-440 (2009).

Wetzel, R.G.: Land-water interfaces metabolic and limnological regulators. Verhandlungen der Intertionalen Vereinigang fur theoretische und angewandte Limnolgie, 24, 6-24 (1990).

Wong, C.K., E.Y.W. Yau and A.A.Y. Lie: The seasonal distribution, diel vertical distribution and feeding behavior of Paraeuchaeta concinna in the shallow subtropical coastal waters of eastern Hong Kong. Aquat. Biosyst., 8, 1-12 (2012).

Wong, G.T.F., S.Y. Chao, Y.H. Li and F.K. Shiah: The Kuroshio edge exchange processes (KEEP) study-and introduction to hypotheses and highlights. Cont. Shelf Res., 20, 335-347 (2000).

Yen, J., B. Sanderson, J.R. Strickler and A. Okubo: Feeding currents and energy dissipation by Euchaeta rimana, a subtropical pelagic copepod. Limnol. Oceanogr., 36, 362-369 (1991).

Zheng, L., B. Chen, X. Liu,B. Huang, H. Liu andS. Song: Seasonal variations in the effect of microzooplankton grazing on phytoplankton in the East China Sea. Cont. Shelf Res., 111, 304$315(2015)$.

Zuo, T., R. Wang, Y.Q. Chen, S.W. Gao and K. Wang: Autumn net copepod abundance and assemblages in relation to water masses on the continental shelf of the Yellow Sea and East Sea. J. Mar. Syst., 59, 159-172 (2006). 